\title{
TALUS PARTITUS
}

\author{
A CASE REPORT
}

ADAM SCHREIBER, PAUL DIFFERDING, HANS ZOLLINGER

From the Department of Orthopaedic Surgery, University of Zurich/Balgrist

\begin{abstract}
A 15-year-old girl presented with a four-year history of pain in the left ankle. There was no known trauma, only a postnatal soft tissue infection which had healed with no sequelae. Radiographs showed that the talus consisted of two large fragments and one small one.
\end{abstract}

\section{CASE REPORT}

A 15-year-old girl presented with a four-year history of pain in the left ankle. There was no history of injury. A minor infection of the soft tissues lateral to the ankle had occurred eight days after birth: this was treated conservatively and healed without sequelae. She now complained of a dull ache located principally over the medial malleolus: it occurred after certain sports such as jumping and running. She also noticed slight swelling, but had no feeling of instability.

The foot looked normal in shape, apart from some swelling behind the medial malleolus. Plantarflexion was full but dorsiflexion limited; supination and pronation also were limited and were painful.

A third fragment was suspected and was confirmed by lateral tomography (Fig. 1). A lateral radiograph (Fig. 2) showed a cleft in the middle of the talus and some flattening of its upper surface. During arthrography (Figs 3 and 4), the contrast medium flowed from the ankle through the cleft to the subtalar joint. Scintigraphy with technetium (Fig. 5) showed augmented activity in that area.

Symptoms were slight and it was felt that no intervention was indicated.

\section{DISCUSSION}

We have searched the pertinent literature for cases similar to ours (Marti 1947; Hirschtick 1951) and we found that anatomists (Turner 1883; Bennett 1887) have described a discrete ossicle which is sometimes present on the posterior border of the talus; they believed that this represented a secondary centre of ossification. The only

A. Schreiber, MD. Professor and Chairman

P. Differding. MD

H. Zollinger. MD

Department of Orthopaedic Surgery. University of Zurich/Balgrist. Forchstrasse 340, 8008 Zurich. Switzerland.

Requests for reprints should be sent to Dr Zollinger.

(. 1985 British Editorial Society of Bonc and Joint Surgery (0) $301-620 \times \times 53082 \$ 2.00$

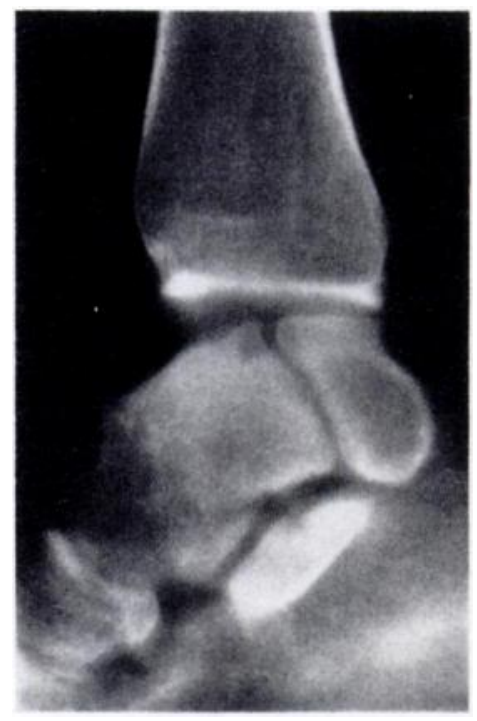

Fig. 1

Lateral view of the left foot. Tomography shows a third fragment and a subchondral cyst.

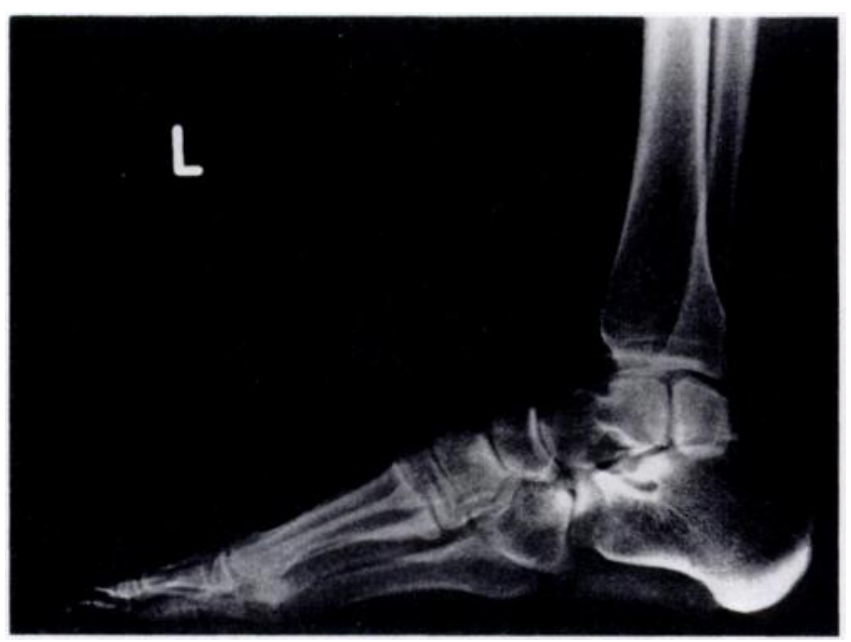

Fig. 2

Radiograph shows that in addition to the cleft in the middle of the talus there is flattening of its upper surface. 


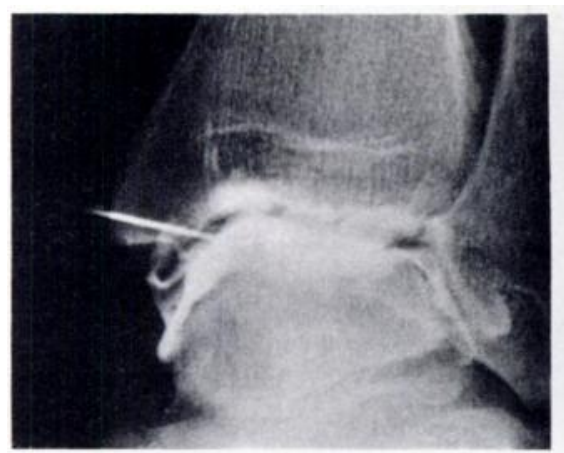

Fig. 3

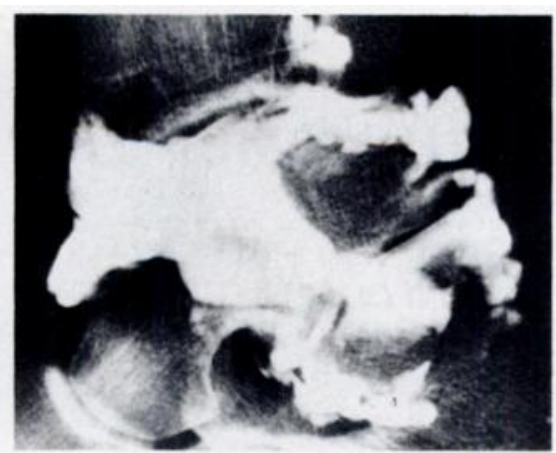

Fig. 4

Figures 3 and 4-Arthrography of the talar joint: no cleft is seen on the anteroposterior view. The contrast medium flowed from the ankle through the cleft to the subtalar joint. Figure 5-Scintigraphy with technetium, showing augmented activity at the upper part of the talus.
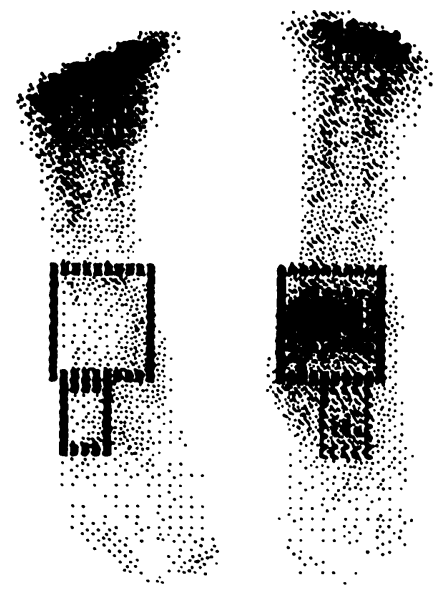

Fig. 5 recent article on such a case was by Weinstein and Bonfiglio (1975): they excised a fragment measuring $2.5 \times 2 \mathrm{~cm}$ and covering the entire posterior talocalcaneal surface as well as part of the upper surface of the talus. Our patient did not have enough pain to warrant surgery so that the origin of the fragment must remain speculative. There was no history of trauma, and the infection, which healed uneventfully, can hardly be incriminated.

The question arises whether the large fragment in our patient could represent a secondary centre of ossification. Although the talus is usually said to ossify from one major centre, which appears during the seventh month of gestation, secondary centres have been described. Usually they have a rounded posterior border and later fuse with the main portion of the bone. They may, however, remain separate and occasionally be associated with pain sufficient to justify excision. We think that the fragment in our patient probably has arisen from a secondary centre of ossification. The remarkable feature is its large size and the fact that symptoms were so slight that excision, which might have revealed the origin, was not needed.

\section{REFERENCES}

Bennett EH. On the ossicle occasionally found on the posterior border of the astragalus. J Anat Phisiol 1887:21(NS1):59-65.

Hirschtick AB. An anomalous tarsal bone. J Bone Joint Surg [Am] 1951:33-A:907-10.

Marti T. Die Skelettvarietäten des Fusses: ihre klinische und unfallmedizinische Bedeutung. Bern: Hans Huber, 1947:45-60.

Turner W. A secondary astragalus in the human foot. $J$ Anat Physiol 1883:17:82-3.

Weinstein, SL, Bonfiglio M. Unusual accessory (bipartite) talus simulating fracture: a case report. J Bone Joint Surg $[\mathrm{Am}]$ 1975:57-A: $1161-3$. 